\title{
Medical radiation exposure of pregnant patients: case study of the gynaeco obstetric and paediatric hospital of douala,
} cameroon

\author{
Simo A, Beyala Ateba JF*, Ndjaka Manyol E, Ndzana Ndah T, Ndontchueng MM, Ndi SR and Njiki CD \\ National Radiation Protection Agency of Cameroon, Yaoundé, Cameroon
}

\begin{abstract}
The use of X-Ray in medical radiology is always risky. In particular, when it comes to imaging pregnant women, the majority of foetus cells might be damaged. Despite all the requirements from international renowned organizations relating to imaging of pregnant women and newborns, the unintentional irradiations of the foetus are still common in radiology services. A case that occurred at the Gynaeco Obstetric and Paediatric Hospital of Douala (Cameroon) in September 2015, is instructive. A 46-year-old woman about six months pregnant was subject to an X-Ray of the pelvis requested by a medical doctor following a suspicion "of osteonecrosis". Investigations have been conducted by the National Radiation Protection Agency (NRPA) by using Diavolt kVp meter. In addition, theoretical foetal dose estimation has been proceeded to evaluate accuracy of the technical estimation of the obtained result. The patient was irradiated with parameters of $20 \mathrm{mAs}$ and $90 \mathrm{kV}$ which lead to a dose to foetus of about $213 \mu \mathrm{Gy}$. The lead apron that was used to protect the pelvis reduced the absorbed dose by a factor of 6 . The hospital officials were advised to do more collaboration between referral medical doctors and radiologists as soon as the use of X-Ray on pregnant women is deemed necessary, to inform patients about the dangers of ionizing radiation on foetus, and to request information on their pregnancy status as well.
\end{abstract}

\section{Introduction}

The use of X-ray generators for diagnostic radiology in the medical sector in Cameroon, Central Africa, is wide spread and on the increase in recent times [1]. One of the most commonly asked questions in relation to the use of ionizing radiation in medicine concerns the management of the pregnant patient. Instinctively, one might want to avoid use of radiation with a pregnant patient; however, there are a number of situations in which the use of radiation for diagnosis or therapy is appropriate. In addition, there are many female physicians and technicians who are employed in medical settings involving radiation. Thousands of pregnant patients and radiation workers are exposed to ionizing radiation each year [2]. $\mathrm{X}$ rays have also been used for more than 50 years to assess the dimensions of the maternal pelvis in pregnancy [3]. For occupationally exposed pregnant women, the equivalent dose to the surface of the abdomen shall not exceed $2 \mathrm{mSv}$ per year and the effective dose resulting from exposure shall not exceed $1 \mathrm{mSv}$ from the time which the pregnancy is known until its term [4,5]. According to presidential decree $\mathrm{N}^{\circ} 2002 / 250$, issued on 31st October 2002, National Radiation Protection Agency (NRPA), was established as the only Regulatory Body in Cameroon [6]. It is the competent authority for radiation protection and waste management issues. In this frame, the NRPA authorizes and controls the use of ionizing radiation sources to protect people and the environment against the harmful effects of radiation.

Since the Decree $\mathrm{N}^{\circ} 2002 / 250$ states in article 4 (5) that, the NRPA is responsible to respond to radiological accident/incident, it has been notified of the radiological incident related to the irradiation of the fetus with X-ray machine occurred at the Gynaeco Obstetric and Paediatric Hospital of Douala, Cameroon.
According to this notification, NRPA team carried out an investigation mission for estimating the dose to the fetus. This paper gives operational measures of management of the concerned incident. These measures will be shared in the whole medical sector in Cameroon to avoid similar cases.

\section{Material and method}

\section{Management of a pregnant patient}

According to ICRP publication 84, NRPA has put in place some measures to manage pregnant patients in diagnostic radiology. Before $\mathrm{X}$-ray examination, it should be determined whether a patient is, or may be, pregnant and whether the fetus will be in the direct beam. In addition, advisory notices should be posted at several places within diagnostic X-ray departments and areas where diagnostic X-ray equipment is used to avoid unintentional radiation exposures of the embryo and fetus.

When a patient has been determined to be pregnant or possibly pregnant, the radiologist usually begins by determining whether the fetus is going to be in the primary X-ray beam. If not, then the risk to the fetus is extremely low and the most important thing is to keep the number and type of exposures to a minimum while still getting the correct diagnosis.

When an examination is indicated in which the X-ray beam irradiates the fetus directly, and this cannot be delayed until after

Correspondence to: Beyala Ateba JF, National Radiation Protection Agency of Cameroon, Yaoundé, Cameroon, E-mail: bajeanfelix@yahoo.fr

Received: March 03, 2018; Accepted: March 20, 2018; Published: March 24 2018 
pregnancy, the most common ways to tailor examinations and reduce fetal exposure are to collimate the beam to a very specific area of interest.

When a high-dose procedure is performed and when the fetus is known to be in the primary X-ray beam, the technical factors should be recorded to allow subsequent fetal dose estimation.

\section{Experimental fetal dose estimation}

The NRPA investigation protocol has been used to measure entrance skin dose (ESD) of the pregnant woman. According to Mahadevappa in 2011, foetal dose be conservatively estimated as 0.15 times the entrance skin dose (ESD) for conventional radiography and fluoroscopy techniques [7].

DIAVOLT $\mathrm{kVp}$-meter which is non-invasive $\mathrm{kVp}$, PPV, dose and time meter for acceptance tests and quality control (QC) of diagnostic $\mathrm{X}$-ray equipment has been used for the measurements. According to the NRPA Guidance $\mathrm{N}^{\circ} 0050$ (2016) on quality control of X-ray machine in diagnostic radiology, steps given below were followed [8].

- Mode RAD/FLU has been chosen;

- $\mathrm{kVp}$ ranged from 40 to $150 \mathrm{kV}$ has been setted;

- filtration of $2.5 \mathrm{mmAl}$ as indicated on the tube has been chosen;

- DIAVOLT $\mathrm{kVp}$ meter was positioned on the top of table at $100 \mathrm{~cm}$ of X-ray tube;

- light field was collimated on the size of the DIAVOLT;

- $20 \mathrm{mAs}$ and $90 \mathrm{kV}$ have been chosen for tests;

- three measures of ESD have been recorded.

The DIAVOLT kVp meter was covered by a lead apron of 0.25 $\mathrm{mmPb}$ to reproduce conditions of the examination for which physical parameters are given below:

- Source to image receptor distance is 1meter;

- Tube potential setting is $90 \mathrm{kV}$;

- Tube current setting $200 \mathrm{~mA}$;

- Exposure time 0.1 second;

- Beam size: $43 \mathrm{~cm}$ x $35.5 \mathrm{~cm}$;

- Patient AP thickness is $26 \mathrm{~cm}$;

- Total filtration $2.5 \mathrm{mmAl}$.

\section{Theoretical fetal dose estimation}

An accurate approach to provide an estimation of fetal dose, either prospectively or retrospectively is to assess the dose for the individual patient using the technique parameters that were used for the patient's examination and taking into account both fetal depth and size [9]. Specific values for the following parameters were requested: projection and view for each examination, filtration, source-to-imager receptor distance, machine outputs, and techniques parameters $(\mathrm{kVp}$, tube current, exposure time, etc.) used for the examination(s).

According to the NCRP report 54, the basic information that is required to estimate the dose to the embryo-fetus from radiographic examinations is the air exposure rate at some reference point and the half-value layer (HVL) [10].
The estimated exposure rate in air $(\mathrm{mR} / \mathrm{mAs})$ as a function of $\mathrm{kVp}$ and total aluminum filtration at 1 meter from the $\mathrm{x}$-ray source can be obtained from Schulz and Gignac data (1976) for three phase equipment [11].

If the total filtration is known, the HVL may be estimated from NCRP report 33 published in 1968, for three phase and constant potential equipment [12].

The exposure rate in air can be determined at the source-skin distance (SSD) used by inverse square extrapolation.

\section{Result and discussion}

Table 1 shows doses measured by Diavolt $\mathrm{kVp}$ meter with lead apron on it. The mean value of about $1420 \mu \mathrm{Gy}$ was obtained. This value has been used to estimate a fetal absorbed dose which is found to be $213 \mu \mathrm{Gy}$ according to Mahadevappa in 2011.

Effectiveness of the shielding enclosed in lead apron has been appreciated through ratio between doses measured by Diavolt without and cover with lead apron. Therefore, the shielding used to cover the pelvic attenuated the direct beam by a factor of about 6 .

According to the data collected from Schulz and Gignac curve on exposure rate in air at $1 \mathrm{~m}$ from the $\mathrm{X}$-ray source and following data from NCRP report 33 where HVL is estimated as a function of tube potential for three phase generators, table 2 has been obtained by taking into account characteristics of $x$-ray source (Table 3 ) and exposure parameters. Total exposure at $1 \mathrm{~m}$ is given by the following relation:

$$
\begin{aligned}
\text { Total Exposure at } 1 \mathrm{~m}(\mathrm{mR})= & \text { courant }(\mathrm{mAs}) \times \text { numberofexposure } \\
& \times \text { exposure rate in air }\left(\frac{\mathrm{mR}}{\mathrm{mAs}}\right)
\end{aligned}
$$

Exposure in air at the source skin distance (SSD) is given by:

$$
\text { Exposure in air at the } \mathrm{SSD}=\frac{\text { Total Exposure at } 1 \mathrm{~m}}{\mathrm{SSD}^{2}}
$$

In addition, the dose to the uterus per roentgen exposure at the skin has been estimated through the dose to the uterus for 1 roentgen entrance skin exposure from Rosenstein (1976) data reported by NCRP report 54 [13].

According to the above-mentioned procedure, the theoretical dose to the uterus has been found to be $1.8 \mathrm{mGy}$. Since the lead apron used for the exam reduced the absorbed dose by a factor of 6 , it can be assumed that the received fetal dose will be approximately $300 \mu \mathrm{Gy}$.

Theoretical fetal dose estimation has been proceeded to evaluate accuracy of the experimental fetal dose estimation. The results are tabulated in table 4 together with those obtained theoretically. The fetal dose estimated is in agreement within $29 \%$.

According to ICRP 84, Estimation of the absorbed dose to the embryo or fetus from plain film abdominal or pelvic radiography examinations is difficult, but usually the dose can be estimated within a $50 \%$ error. In addition, measurements at 20 centres in the United Kingdom with an anthropomorphic phantom of a pregnant woman at full term revealed mean fetal doses varying by a factor of up to about 40 [14]. The present study, which is a contribution to the estimation of the dose to the fetus, confirms the fact that fetal dose is not easily accessible. The obtained value which is $213 \mu \mathrm{Gy}$ is less than $100 \mathrm{mGy}$ above which malformations may be suspected. This dose is relatively low and cannot be responsible for deterministic effects. However, it presents a minor 
Table 1. Doses measured by Diavolt with lead apron on it.

\begin{tabular}{|c|c|c|c|c|c|c|c|c|}
\hline $\begin{array}{l}\text { Tube potential } \\
(\mathbf{k V})\end{array}$ & View & Courant (mAs) & $\begin{array}{l}\text { Total filtration } \\
\quad(\mathrm{mmAl})\end{array}$ & $\begin{array}{l}\text { Beam size }(\mathrm{cm} \\
\quad x \mathrm{~cm})\end{array}$ & $\begin{array}{c}\text { Sourceskin } \\
\text { distance (SSD } \\
\text { in } \mathrm{cm})\end{array}$ & $\begin{array}{c}\text { Exposure rate in } \\
\operatorname{air}(\mathrm{mR} / \mathrm{mAs})\end{array}$ & $\begin{array}{l}\text { Half value layer } \\
\quad(\mathrm{mmAl})\end{array}$ & Uterus dose / $\mathbf{R}$ \\
\hline 90 & AP & 20 & 2.5 & $43 \times 35.5$ & 100 & 14 & 3.1 & 353 \\
\hline
\end{tabular}

Table 2. Uterus dose per roentgen estimated through technical parameters.

\begin{tabular}{|c|c|c|c|}
\hline Parameters & Essay No & Measured Entrance Skin dose $(\mu$ Gy) & 1420 \\
\hline & 1 & 1421 \\
\hline $\mathbf{2 0 m A s}$ & 2 & 1419 \\
\hline & 3 & $\mathbf{1 4 2 0}$ \\
\hline
\end{tabular}

Table 3. Characteristics of X-ray tube.

\begin{tabular}{|c|c|c|c|c|c|}
\hline Supplier & SN & Model & mA Max & kV - Max & Filtration (mmAl) \\
\hline $\begin{array}{c}\text { China } \\
\begin{array}{c}\text { RessourcesWandong } \\
\text { Medical EquipmentCo. } \\
\text { Ltd }\end{array}\end{array}$ & 1205141 & DX52-30.50/125HT2F & $/$ & 125 \\
\hline
\end{tabular}

Table 4. accuracy of the results.

\begin{tabular}{|c|c|c|c|}
\hline Exam parameters & Experimental foetal dose estimated $(\boldsymbol{\mu G y})$ & Theoritical foetal dose estimated ( $\boldsymbol{\mu G y )}$ & Deviation (\%) \\
\hline $90 \mathrm{kV}, 20 \mathrm{mAs}$ & 213 & -29 \\
\hline
\end{tabular}

risk of cancer and leukemias for children aged from 0 to 15 years whose mothers have undergone irradiation during pregnancy.

According to the responsibilities of actors, the risk of cancer in teenage year must be taken into account in the follow-up of the pregnant woman by emergency physician and the radiologist. The need to justify any X-ray examination in this case and possibly to use nonirradiating imaging with equal diagnostic performance is advised.

If the proposed radiological examination is the only one to be able to establish the diagnosis necessary for the appropriate therapeutic management, emergency physician and the radiologist is required to inform the patient of the risks of malformations and cancers that can occur.The radiologist is responsible for mentioning the estimated dose of irradiation on the examination report. The medico-legal responsibility of the interveners imposes in addition to the justification, taking into account prenatal and postnatal risks.

\section{Conclusion}

In general, the medical follow-up of pregnant women is delicate and requires the collaboration of all the stakeholders. The ignorance of the effects of ionizing radiation on the fetus by some medical staffs and the insufficient collaboration between them can be considered as the main causes of the incidents. At the same time, the irradiation of a pregnant woman must be the subject of a documented consensus between medical staffs. A report specifying the dose received in the abdomen must be drawn up by the radiologist and archived in the department. The patient's information on the risks that can occur during the irradiation is prior to the $\mathrm{X}$-ray exam.

According to this incident, it has been recommended to diagnostic radiology in medical sector in Cameroon to:

- Justify any X-ray examination required for a pregnant woman when non-irradiating imaging cannot be used;

- establish mechanisms for collaboration between medical personnel involved in the follow-up of pregnant women in order to take into account effects of ionizing radiation on the fetus and / or teenage year;
- put in place mechanisms for informing pregnant women about the risks to the fetus and / or teenage year when it is undergoing irradiation;

- put in place mechanisms for early notification of incidents;

- carry out training in radiation protection of personnel involved in radiology.

These measures are now shared during implementation of NRPA inspection program in the whole medical sector in Cameroon.

\section{Acknowledgment}

The authors thank IAEA for their continuous efforts and technical support in the NRPA activities.

\section{References}

1. Beyala Ateba JF, Simo A, Moyo M, Sabouang JF (2017) Operational measures taken for the authorization of X-ray generators used in the medical sector in Cameroon. Health Phys 113: 414-418. [Crossref]

2. ICRP (2000) Pregnancy and Medical Radiation. Ann ICRP 30: 1-43. [Crossref]

3. UNSCEAR (2000) Annex D: Medical radiation exposure. United Nations publication, New York.

4. ICRP (1991) 1990 Recommandations of the International Commission on Radiological Protection. Ann ICRP 21: 1-201. [Crossref]

5. Ministry of Health of the Republic of Cameroon (2013) Arête $\mathrm{N}^{\circ} 1152$ on modalities of detention and use of $\mathrm{x}$-ray machines in medical sector. Yaounde.

6. Decree $\mathrm{N}^{\circ} 2002 / 250$ of 31 October 2002 to set up, organize and regulate the functioning of the National Radiation Protection Agency. Official Gazette of the republic of Cameroon 2003.

7. Mahadevappa M (2011) Dosimetry in Pregnant Patients undergoing CT and Fluoroscopy. Joint American Association of Physicists in medicine (AAPM)/COMP meeting. Vancouver, Canada.

8. National Radiation protection Agency NRPA (2016) Guidance $\mathrm{N}^{\circ} 0050$ on QC of X-ray machine in diagnostic radiology.

9. Osei EK, Darko J (2012) Foetal radiation dose and risk from diagnostic radiology procedures: a multinational study. ISRN Radiol 2013: 318425. [Crossref]

10. NCRP Report $\mathrm{N}^{\circ} 54$ Medical radiation exposure of pregnant and potentially pregnant women, Bethesda, Maryland1977. 
11. Schulz RJ, Gignac C (1976) Application of tissue-air ratios for patient dosage in diagnostic radiology. Radiology 120: 687-690. [Crossref]

12. NCRP (1968) National Council on Radiation Protection and Measurements, Medical $\mathrm{X}$-Ray and Gamma- Ray Protection for Energies up to $10 \mathrm{MeV}$-Equipment Design and Use, Report No. 33, Washington.
13. Rosenstein M (1976) Organ Doses in Diagnostic Radiology, DHEW Publication (FDA) 76- 8030 (U.S. Government Printing Office, Washington).

14. Badr I, Thomas SM, Cotterill AD, Pettett A, Oduko JM, et al. (1997) X- ray pelvimetry - Which is the best technique? Clin Radiol 52: 136-141. [Crossref]

Copyright: $\mathbb{0} 2018$ Simo A. This is an open-access article distributed under the terms of the Creative Commons Attribution License, which permits unrestricted use, distribution, and reproduction in any medium, provided the original author and source are credited. 